\title{
Review
}

\section{Plant SWEET Family of Sugar Transporters: Structure, Evolution and Biological Functions}

\author{
Jialei Ji *, Limei Yang, Zhiyuan Fang, Yangyong Zhang, Mu Zhuang, Honghao Lv (D) and Yong Wang
}

check for updates

Citation: Ji, J.; Yang, L.; Fang, Z.; Zhang, Y.; Zhuang, M.; Lv, H.; Wang, Y. Plant SWEET Family of Sugar Transporters: Structure, Evolution and Biological Functions. Biomolecules 2022, 12, 205. https:// doi.org/10.3390/biom12020205

Academic Editor: Attila Fehér

Received: 18 December 2021

Accepted: 18 January 2022

Published: 25 January 2022

Publisher's Note: MDPI stays neutral with regard to jurisdictional claims in published maps and institutional affiliations.

Copyright: (C) 2022 by the authors. Licensee MDPI, Basel, Switzerland. This article is an open access article distributed under the terms and conditions of the Creative Commons Attribution (CC BY) license (https:// creativecommons.org/licenses/by/ $4.0 /)$.

\author{
Key Laboratory of Biology and Genetic Improvement of Horticultural Crops, Ministry of Agriculture, \\ Institute of Vegetables and Flowers, Chinese Academy of Agricultural Sciences, Beijing 100081, China; \\ yanglimei@caas.cn (L.Y.); fangzhiyuan@caas.cn (Z.F.); zhangyangyong@caas.cn (Y.Z.); zhuangmu@caas.cn (M.Z.); \\ lvhonghao@caas.cn (H.L.); wangyong03@caas.cn (Y.W.) \\ * Correspondence: jijialei@caas.cn; Tel.: +86-10-82108756
}

\begin{abstract}
The SWEET (sugars will eventually be exported transporter) family was identified as a new class of sugar transporters that function as bidirectional uniporters/facilitators and facilitate the diffusion of sugars across cell membranes along a concentration gradient. SWEETs are found widely in plants and play central roles in many biochemical processes, including the phloem loading of sugar for long-distance transport, pollen nutrition, nectar secretion, seed filling, fruit development, plant-pathogen interactions and responses to abiotic stress. This review focuses on advances of the plant SWEETs, including details about their discovery, characteristics of protein structure, evolution and physiological functions. In addition, we discuss the applications of SWEET in plant breeding. This review provides more in-depth and comprehensive information to help elucidate the molecular basis of the function of SWEETs in plants.
\end{abstract}

Keywords: SWEET; sugar transporter; phloem loading; plant-pathogen interaction; abiotic stress

\section{Introduction}

Sugar is an important energy source for plants and a necessary carbon source for the synthesis of many of their metabolic intermediates [1-4]. Since sugar is the main transportable form of energy, it participates in the storage and transportation of nutrients in plants and plays an important role in signal transduction and resistance to stress [5-9]. The ability of plants to store sugar is essential for their adaptation to endogenous or environmental factors and the economic value of crops, and plants rely on the energy provided by sugars to complete their processes of growth, development and reproduction. In addition, the processes of sugar production, transportation and metabolism not only communicate information on metabolic processes, such as protein, lipid and nucleic acid metabolism, but also communicate information on the metabolism of secondary substances. Moreover, the osmotic potential of cells is affected by the decomposition of sugars, which, in turn, affects the opening and closing of stomata and the division of anthers and plays a central role in the metabolism, growth and development of plants [9-15].

Sugar in plants is primarily synthesized by photosynthesis in leaves during the day or from the degradation of starch at night [16-20]. During the day, the triose phosphate synthesized in the chloroplast matrix is exported to the cytoplasm and used to synthesize sucrose. At night, the starch in the chloroplast is hydrolyzed into maltose and glucose, which are exported to the cytoplasm and continue to synthesize sucrose. Sucrose invertase and sucrose synthase can metabolize sucrose to monosaccharides [21,22]. The sugar synthesized in the source tissues needs to be transported and distributed to the sink tissues to maintain normal plant growth and development. The transportation and distribution of sucrose, glucose and fructose require the participation of sugar transporters [5].

A variety of monosaccharide and sucrose transporters have been identified in plant plasma membranes or vacuolar membranes, including SUTs (sucrose transporters), MSTs 
(monosaccharide transporters) and SWEETs (sugars will eventually be exported transporters) $[1,5,6]$. Because the primary product of photosynthesis is sucrose, it is the main carbohydrate that is transported in plants. It is primarily transported and redistributed over long distances through the phloem [23-27]. The loading and unloading of phloem sucrose and the transportation of sucrose across cell membranes and vacuolar membranes require the participation of SUTs [27-29]. The transport process that involves sucroseproton symporters, SUTs and MSTs, requires energy to complete the transmembrane transport of sugars [24,30]. SWEETs are a new type of sugar uniporters that can transport sugars in two directions and promote the diffusion of sugars along a concentration gradient $[5,10,31]$. Studies have shown that SWEETs participate in important physiological processes of plant growth and development by regulating the transportation, distribution and storage of carbohydrates [32,33]. This review introduces the progress of research on the discovery, structural characteristics, physiological functions and regulation of stress by the SWEET gene family, which is of substantial significance to enhance plant breeding efforts in the future.

\section{Discovery of SWEET Sugar Transporters}

The fluorescent resonance energy transfer (FRET) sensor is a novel fluorescent signal label that is expressed in plants and animals and quantifies the intensity of fluorescence signal so that changes in the concentrations of substrates, such as sugars, amino acids and ions, at the cellular and subcellular levels, can be monitored in living tissues in real time $[34,35]$. Chen et al. [35] used the glucose FRET sensor to identify a new type of sugar transporter from Arabidopsis thaliana, designated SWEET. SWEET proteins use the concentration gradient of intracellular and extracellular sugars to transport them across membranes instead of relying on the proton gradient $[6,10]$. Thus, the ability of SWEET proteins to transport sugar does not depend on the $\mathrm{pH}$ value of the environment. Moreover, SWEET proteins can transport sugar in both directions across the membrane along a concentration gradient driven by solute potential $[6,10]$. In other words, SWEET proteins can transport sugar from within cells to the extracellular milieu or from extracellularly to intracellularly along the concentration gradient of sugar. While the MSTs and SUTs that have been identified require coupling with $\mathrm{H}^{+}$, they use the $\mathrm{H}^{+}$concentration gradient inside and outside of the cell to transport sugar in one direction across the membrane [27,36,37].

It is hypothesized that many important physiological processes of plants, such as phloem loading and nectar secretion, may require the participation of sugar efflux transporters [36]. However, before the discovery of the SWEET gene family, such sugar transporters had not been isolated, resulting in an incomplete understanding of the molecular and physiological mechanisms of these important physiological processes in plants. The discovery of the sugar efflux transporter SWEET plays a pivotal role in understanding the molecular mechanisms of these important physiological processes in plants.

In fact, SWEETs are widespread in prokaryotes, animals and plants. However, compared with plants, there are fewer members of the SWEET gene family in prokaryotes and animals. For example, Mycoplasma arthritidis, Prochlorococcus marinus, mice (Mus musculus), olive baboon (Papio anubis) and humans all have only one SWEET gene [38,39]. A total of $17,21,29,105,52,27,18$ and 17 SWEET genes have been identified from the vascular plants A. thaliana, rice (Oryza sativa), eggplant (Solanum melongena), wheat (Triticum aestivum), soybeans (Glycine max), poplar (Populus trichocarpa), pears (Pyrus spp.) and grapes (Vitis vinifera), respectively [35,38-44]. Different members of the SWEET family from the same plant can transport different sugars. For example, $A$. thaliana AtSWEET2 transports 2-deoxyglucose, AtSWEET17 transports fructose, and AtSWEET11, -12 and - 16 can transport sucrose, glucose and fructose [45-48]. Moreover, different members of the SWEET family of the same species vary in their characteristics of expression in different tissues [6,35,42]. These results suggest that the SWEETs have a variety of important physiological functions in plants. 


\section{Structural Characteristics of the SWEETs}

Before the discovery of SWEETs, the MSTs and SUTs that had been identified in plants were members of the major facilitator superfamily (MFS). The $\mathrm{N}$-terminal and C-terminal ends of these proteins are both located on the intracellular side and typically contain $12 \alpha$-helical transmembrane domains (TMs). There is a large cytoplasmic loop located on the intracellular side in the middle of the MFS protein, which divides the protein into two domains $[26,49,50]$. The $\mathrm{N}$-terminal and C-terminal domains each contain six TMs. The topological structures of these two domains are very similar and exist in a pseudo-quadratic axisymmetric manner. The six TMs that form each domain can be split into two groups of three TMs that symmetrically repeat units in an anti-parallel manner $[26,49,50]$. This unique folding method is designated MFS fold [51].

The plant SWEETs are members of the MtN3/saliva family (PF03083). Its N-terminus and C-terminus are located on the outside and inside of the cytoplasm, respectively. Plant SWEETs generally contain seven TMs (Figure 1a,b). The fourth TM is less conservative and primarily acts as a link. It divides the protein into two MtN3/saliva domains that each contain three TMs that form a "3-1-3" structure [10]. The three TMs of each MtN3/saliva domain are arranged in the form of "TM1-TM3-TM2" to form a triple-helix bundle (THB) (Figure 1a,b). It is apparent that the topological structure of SWEETs differs significantly from those of MSTs and SUTs. This difference could be an important reason why SWEET can transport sugar intracellularly to extracellularly. In addition, the SWEETs of prokaryotes only contain one MtN3/saliva domain composed of three TMs [52]. Therefore, they have been designated SemiSWEETs. It can be hypothesized that one MtN3/saliva domain in prokaryotes underwent replication or horizontal gene transfer, which is defined as the transmission of DNA between different genomes, during the process of evolution, which led to the production of SWEET proteins in eukaryotes that contain two MtN3/saliva domains.

The results of truncation and complementation experiments demonstrated that SWEETs must undergo oligomerization to form homologous or heteromultimers to transport sugars [52]. The most likely scenario is that the eukaryotic SWEETs form dimers, while the prokaryotic SemiSWEETs form tetramers. A. thaliana SWEET proteins can form at least eight homopolymers and 47 heteropolymers [52] (Figure 1c). A high-resolution threedimensional structural analysis of the bacterial SemiSWEET proteins proved that two SemiSWEET protein monomers form a basic translocation pore unit by forming a symmetrical homodimer [53-56]. In addition, the tryptophan residue from TM2 and the asparagine residue from TM3 are the key sites for the SemiSWEET protein to be able to transport sugars [53-56]. Rice OsSWEET2b was the first eukaryotic SWEET protein for which a three-dimensional structure was resolved [57]. It showed that a single OsSWEET2b protein monomer can form a basic translocation pore unit and that TM4 and THB1 are closely linked to constitute the $\mathrm{N}$-terminal region. In addition, THB2 constitutes the C-terminal region. This explains why the truncation of AtSWEET1 protein into THB1 + TM4 and THB2 and their co-expression enables the transportation of glucose [52]. In contrast, THB1 and TM4 + THB2 that have been truncated and co-expressed cannot transport glucose [52]. Moreover, owing to the inconsistent tightness of TM4 with THB1 and THB2, THB1 and THB2 are structurally asymmetrical, which obviously differs from the symmetrical arrangement of the two THBs in the SemiSWEET homodimer of prokaryotes [57]. Cysteine residues from TM2, asparagine residues from TM3 and TM7 and phenylalanine residues from TM6 are the key sites for OsSWEET2 to transport glucose [57]. Recently, the crystal structure of A. thaliana AtSWEET13 with a resolution of $2.8-\AA$ has been obtained. The researchers observed an inward-facing conformation of AtSWEET13 with the substrate analog 2'-deoxycytidine-5'-monophosphate bound to the central cavity [58]. There are 10 amino acid residues in the AtSWEET13 protein that play an important role in the recognition and binding of substrates. They are designated Ser20 from TM1 (Ser20 ${ }^{\mathrm{TM} 1}$ ),

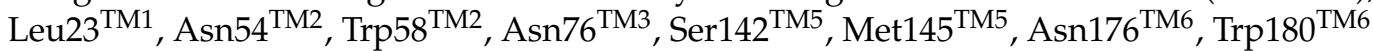
and Asn196 ${ }^{\mathrm{TM} 7}$. Up to now, structural analysis has revealed that SemiSWEET or SWEET proteins have three conformations: outward open conformation, inward open conformation 
and occluded conformation. These results laid a structural foundation to elucidate the mechanism by which the SWEET protein binds to substrates and transports sugar. Based on this, a rocking-type motion theory was proposed [53]. In OsWEET2b, the proline residues on TM1, TM2, TM5 and TM6 may be the key factors that promote the transition between different conformations.

(a)

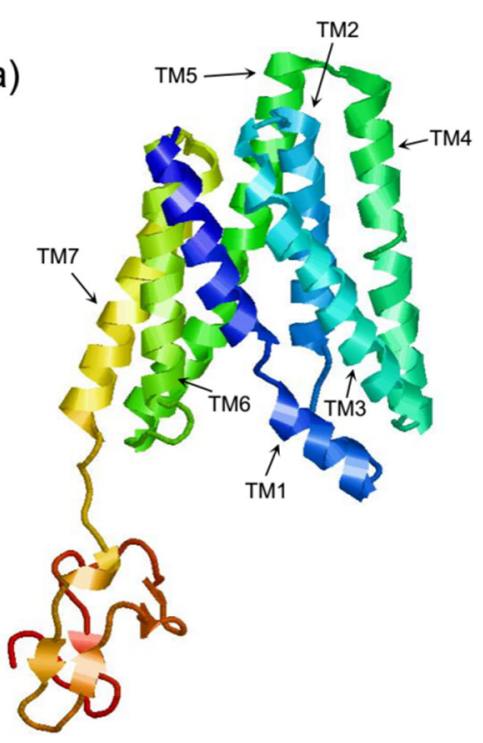

(b)

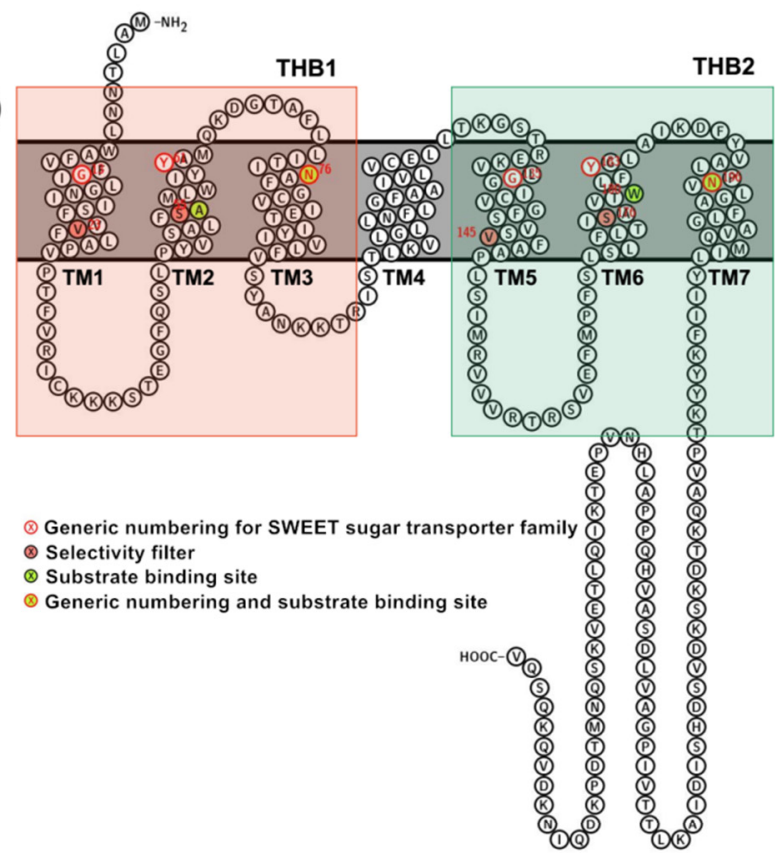

(c)

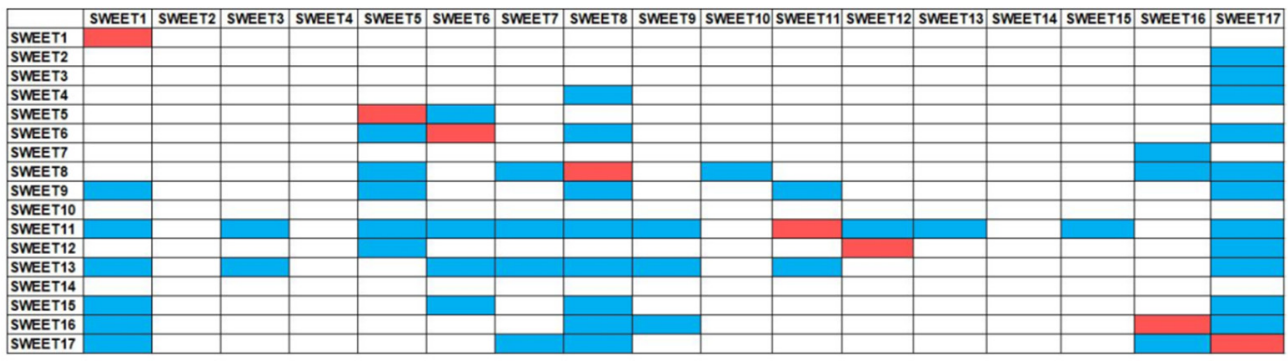

Figure 1. Structural characteristics of SWEETs. (a) The three-dimensional model of AtSWEET13 constructed with Phyre2. (b) Snake diagram of AtSWEET13 with key positions labeled. (c) AtSWEETs interaction matrix diagram [52]. The colored boxes represent interaction between two SWEETs. The red boxes indicate homopolymers, and the blue boxes indicate heteropolymers.

It is worth noting that there is a database designated dbSWEET (http:/ / bioinfo.iitk. ac.in/bioinfo/dbsweet/Home, accessed on 7 December 2021) that contains more than 2000 SWEET members from prokaryotes and eukaryotes. This database helps researchers to more effectively analyze the biological functions of SWEET through targeted gene editing and simulation experiments.

\section{Evolution of the SWEET Gene Family}

Yuan and Wang [38] used the transporter classification database (TCDB; http:/ / www. tcdb.org, accessed on 12 November 2021) to select SWEET proteins of different species for a phylogenetic analysis that revealed that the SWEET proteins in different species can be divided into three evolutionary clades. The SWEET proteins of monocots and dicots are members of Clade I, the SWEET proteins of metazoans and mammals are members of Clade II, and those of the bacteria and archaea are members of Clade III. Some members of the Caenorhabditis elegans MtN3/saliva family in metamorphosis are also included in Clade III. There is only one MtN3/saliva domain composed of three transmembrane 
helices in all the bacterial proteins in branch III. A phylogenetic analysis indicates that the widespread distribution of the MtN3/saliva SWEET protein may originate from the SemiSWEET protein of prokaryotes. Domain duplication occurred during the evolution of eukaryotes, resulting in a protein with seven transmembrane $\alpha$-helices that contains two MtN3/saliva domains.

A further phylogenetic analysis of the SWEETs of 16 types of angiosperms revealed that the family was divided into four subfamilies that are designated Clade I IV (Figure 2), which is consistent with the results of previous studies [39]. Utilizing A. thaliana as an example, the Clade I subfamily contains the three members AtSWEET1, -2 and -3; the Clade II subfamily has five members, including AtSWEET4, -5, -6, -7 and -8; the Clade III subfamily has seven members, including AtSWEET9, -10,-11, -12, -13, -14 and -15; and the Clade IV subfamily has the two members AtSWEET16 and -17. In addition, different subfamilies have selective preferences for monosaccharides or disaccharides. The Clade I and II subfamilies specifically transport hexose, the Clade III subfamily specifically transports sucrose, and the SWEET protein of the Clade IV subfamily is located on the vacuolar membrane and tends to transport fructose [59].

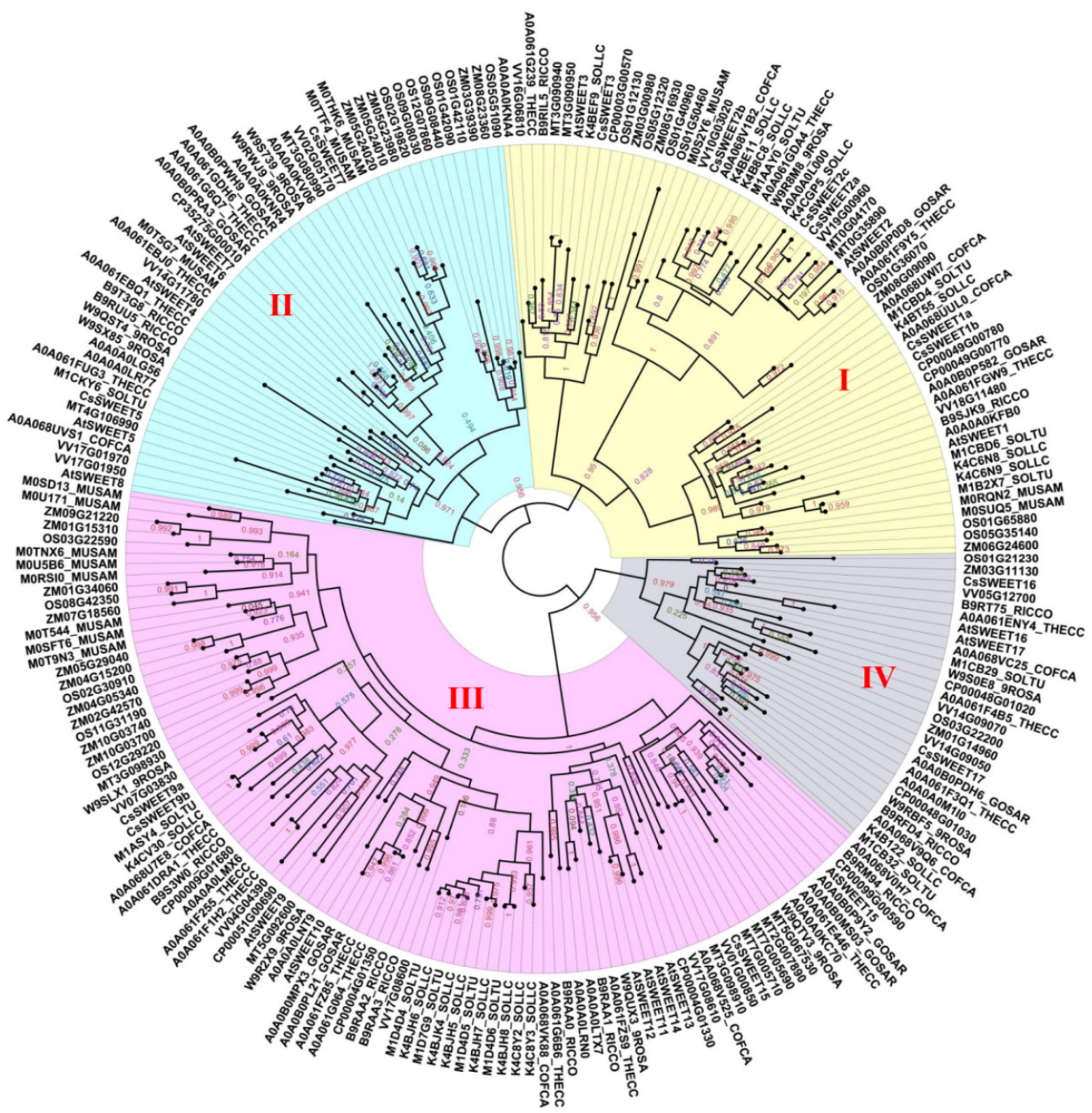

Figure 2. A phylogenetic tree of the SWEETs of 16 types of angiosperms. Accessions were identified from dbSWEET and UniProt. An alignment was conducted using MAFFT (v7.037). Phylogenetic trees were constructed using FastTree (http:/ / www.microbesonline.org/fasttree/, accessed on 25 November 2021) based on the JTT + CAT model. The numerical values in the figure represent the reliability of the clades. The closer the value of the clade is to 1.0, the higher the confidence. 
According to the existing evolutionary analysis, it is believed that the SWEET protein containing 7-TMs and having two MtN3/saliva domains in eukaryotes is produced by duplication of the MtN3/saliva domain containing 3-TMs in prokaryotes. This allows for more complex sucrose transport in eukaryotes [38,39,52]. More interestingly, the SWEET proteins of unicellular algae contain 7-TMs but have not yet formed a conserved THB unit, further speculating that multicellular plants (bryophytes and flowering plants) may acquire 3-TMs from symbiotic bacteria through horizontal gene transfer or possibly obtain 3-TMs through internal duplication.

\section{SWEETs Are Involved in Plant Growth and Development}

\subsection{Participation as a Sucrose Transporter in Phloem Loading}

After the photosynthetic products are synthesized in leaves, they must undergo phloem loading, long-distance transportation and phloem unloading in the sink organs to ensure that the photosynthetic products are transported and distributed between the source and sink tissues. Plants that use sucrose as the main transport form of photosynthetic products primarily conduct their phloem loading through the apoplastic pathway. This pathway involves the transmembrane transport of sucrose and must be completed with the assistance of the corresponding sucrose transporter [60]. Before the discovery of SWEETs, it was not clear what type of transporter assisted the transport of sucrose from the phloem parenchyma cells to the apoplast near the sieve-element-companion-cell complex. This is a prerequisite for sucrose to complete phloem loading in the apoplast pathway. Chen et al. [6] found that AtSWEET11 and AtSWEET12 that are located on the phloem parenchyma plasma membrane are responsible for this process. This was the first proof that the SWEET serves as a carbohydrate efflux carrier to play a key role in the export of sucrose from the phloem apoplast. It provides the prerequisite preparation for the $\mathrm{H}^{+}$/ sucrose cotransporter SUT1/SUC2 to transport sucrose from the apoplast to the sieve-element-companion-cell complex, thus, revealing the entire process of phloem apoplast loading (Figure 3).

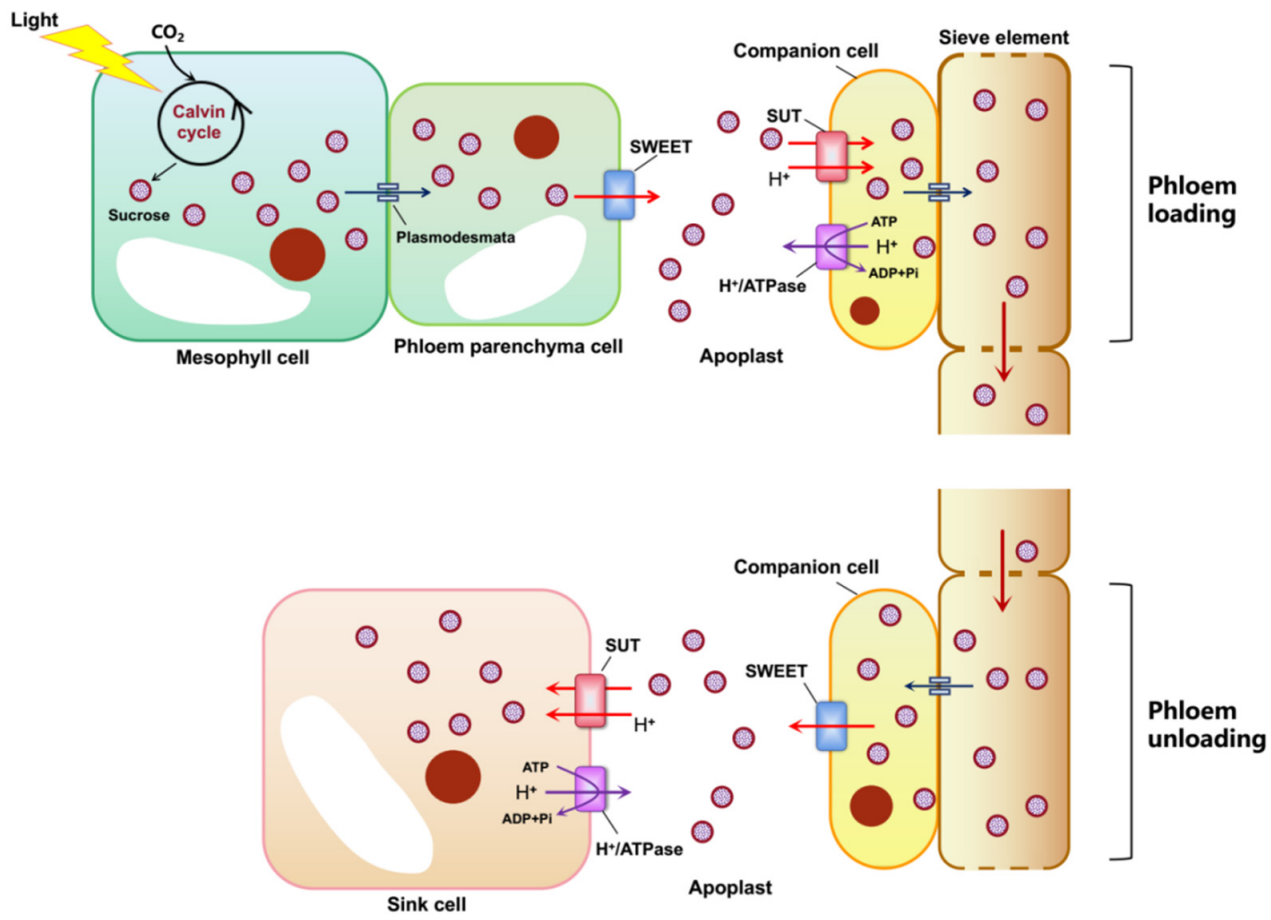

Figure 3. Diagram of phloem loading and unloading. Sucrose synthesized by photosynthesis in mesophyll cells is transported to phloem parenchyma cells through plasmodesmata and then transported to apoplasts near the sieve-element-companion-cell complex (SE-CC) through the SWEET protein. The sucrose is transported to the SE-CC through the $\mathrm{H}^{+}$/sucrose cotransporter SUT1/SUC2 and transported to the sink tissue over a long distance. 
Rice OsSWEET11 is a homologous gene of A. thaliana AtSWEET11 and AtSWEET12 and is also a carrier of low-affinity sucrose transport that is located on the cytoplasmic membrane and primarily expressed in the phloem of rice leaves $[6,61]$. Therefore, it is hypothesized that OsSWEET11 also plays an important role in phloem loading. MtSWEET11 is a nodule-specific sucrose transporter in Medicago truncatula, which participates in the distribution of sucrose in nodules [62].

\subsection{Participation in Male Reproductive Development}

The SWEET gene family in plants is usually involved in the development of pollen and is related to plant fertility. Petunia NEC1 (AtSWEET9) is expressed in nectaries and stamens, particularly in anther stomium cells and upper filaments. Inhibition of the expression of NEC1 leads to premature anther dehiscence, while the pollen is not yet mature, eventually leading to male sterility [63,64]. In A. thaliana, AtSWEET1, AtSWEET5, AtSWEET7, AtSWEET8/RPG1 and AtSWEET13/RPG2 are all expressed in pollen development and may be involved in reproductive development. AtSWEET8 is highly expressed in microspore mother cells and the tapetum. The microspore plasma membrane of the atsweet 8 mutant could not form a regular wavy structure during the tetrad period, which caused the sporopollenin to be deposited abnormally and, finally, led to the degradation of pollen [65,66]. AtSWEET13 is expressed in anthers. Although the pollen exine of the atsweet 13 mutant is slightly defective, the fertility of the mutant does not differ significantly from that of the wild type [66]. AtSWEET13 can partially compensate to improve the fertility of atsweet 8 mutants. The fertility of atsweet8; atsweet13 double mutant was significantly lower than that of the atsweet8 single mutant [66]. These results indicate that AtSWEET8 and AtSWEET13 are partially redundant in terms of plant fertility. AtSWEET8 primarily affects the fertility of early inflorescence, while AtSWEET13 primarily affects the fertility of later inflorescence. In rice, OsSWEET11, which is located on the plasma membrane, is highly expressed in spikelets and pollen. Pollen development of OsSWEET11-silenced plants was arrested at the mononucleate or binucleate stages; the starch content of the pollen is reduced, and the pollen develops poorly, resulting in sterile or semi-sterile plants [67-69].

In addition to the above genes, many SWEETs that may be related to male reproductive development have been identified. There are five members, Cs7g02970, Cs3g14550, Cs3g20720, Cs9g04180 and Cs2g28270, of the SWEET gene family in sweet orange, which are expressed abundantly in flowers [70]. Tomato (Solanum lycopersicum) SISWEET5b/LeSTD1 is the most highly expressed in flowers and specifically expressed in mature pollen grains $[41,71]$. Seven SWEET gene family members in grapes, including VvSWEET3, $-4,-5 a$, $-5 b,-7,-10$ and -11 , are highly expressed in flowers [40]. More than $20 \mathrm{GmSWEET}$ genes in soybean are highly expressed in flowers [39]. Ten CsSWEETs, including CsSWEET5a, $-3 a$, $-9 a,-7 b,-17 a,-9 b,-15 c,-10 c,-1 b$ and $-5 c$, were highly expressed in one or several pollen stages of tea (Camellia sinensis) [72]. Most SWEET genes of watermelon showed high expression levels in male flowers [73]. During the petunia flower development, the expression level of PASWEET13c, $-9 a,-1 d,-5 a$ and $-14 a$ increases with the maturation of the flower [74]. During the anthesis, JsSWEET1, -2, -5, -9, -10, -16 and -17 were highly expressed in the flowers of Jasmine (Jasminum sambac) [75]. The boron-dependent glucose transporter, PwSWEET1, plays a necessary role in Picea wilsonii pollen germination and pollen tube growth [76].

\subsection{Participation in Seed Development}

The ability to transport soluble sugars to developing seeds affects the size and weight of seeds, thereby determining the yield of crops, such as corn (Zea mays), rice and wheat (Triticum aestivum) [77]. The size of seeds increased during the long-term domestication of crops. This selection must be related to the metabolism and transportation of soluble sugars. The expression of the ZmSWEET4c gene in maize and its ancestor species teosinte (Z. mays L. ssp. parviglumis) is quite different [42]. It is speculated that ZmSWEET4c may be a locus related to the regulation of sugar transport during maize domestication. Further research found that ZmSWEET4c is located on the cell membrane of the basal 
endosperm transfer layer. The endosperm of the T-DNA insertion mutant of this gene becomes smaller, and the starch content and weight of the seed are significantly lower than those of the wild-type control, displaying the "empty seed coat" phenotype [42]. These results confirm that $Z m S W E E T 4 c$ has a key role in the filling of corn seeds. Rice OsSWEET4 is homologous to ZmSWEET4c. The OsSWEET4 gene expression level, substrate transport and other characteristics, as well as the mutant plant phenotype, are similar to those of maize ZmSWEET4c. It is hypothesized that this gene can regulate the filling process of rice seeds and is a site that is related to the regulation of sugar transport that evolved during the process of rice domestication.

During the development of $A$. thaliana seeds, the sucrose efflux vectors AtSWEET11, AtSWEET12 and AtSWEET15/SAG29 located on the plasma membrane displayed specific temporal and spatial expression in seeds. The embryos of the three mutant atsweet11;12;15 seeds develop slowly. The seed weight and starch and oil contents are significantly lower than those of the wild type, and the seeds are shrunk and shriveled [78]. In rice, OsSWEET11, OsSWEET14 and OsSWEET15 are highly expressed in caryopses [79-81]. The ossweet11 mutant exhibited a defect in endosperm development, resulting in an empty-seed phenotype with more starch that accumulated in the pericarp [79]. Moreover, ossweet14; ossweet11 and ossweet15; ossweet11 double mutants had a much more severe phenotype than ossweet11 single mutant, including a strongly reduced grain yield and grain-filling rate and increased starch accumulation in the pericarp [80,81]. These results show that OsSWEET11, OsSWEET14 and OsSWEET15 play important roles in rice seed filling.

Soybean seeds require a substantial amount of nutrients from the endosperm to maintain their growth during the early stages of development. Insufficient nutrients can lead to seed abortion and a decrease in yield. GmSWEET15a and GmSWEET15b are primarily expressed in the endosperm of soybean at the cotyledon stage. After these two genes are knocked out, the development of embryos slows, and the content of sugar in the embryo is substantially reduced, which eventually leads to seed abortion [82]. These results indicate that GmSWEET15 plays a role in the development of soybean embryos by mediating the transfer of sucrose from the endosperm to the embryo during early seed development.

\subsection{Participation in Fruit Development}

The soluble sugar content, which primarily refers to sucrose, glucose and fructose, is an important indicator that determines the quality of fruit. Since the SWEET gene family in plants transports sugars, it is logical that they may play a key role in fruit development. The orange (Citrus sinensis) genome contains 16 SWEET genes, with Cs2g28300, Cs3g14550, Cs7g02970, Cs3g14500, Cs3g20720, Cs2g04140 and orange1.1t02627 highly expressed in fruit [70]. The levels of expression of six SWEET genes (VvSWEET4, -7, -10, -11, -15 and $-17 d$ ) in grapes increase with the development of berries [40]. Apple (Malus domestica) MdSWEET1.1/2, MdSWEET2.4 and MdSWEET3.5 are expressed at higher levels in young fruit, while MdSWEET3.6/7 is expressed more abundantly in large fruit [70]. AnmSWEET5 and AnmSWEET11 of pineapple (Ananas comosus) have high expression levels during the early stage of fruit development [83]. Nine SWEET genes in apples are expressed at high levels during fruit development. Among them, MdSWEET9b and MdSWEET15a may be involved in the accumulation of sugar in apples [84]. SISWEET1b, SISWEET1c, SISWEET2a, SISWEET7a and SISWEET14 in tomato are more highly expressed in young fruit, and the expression levels of these five genes gradually decrease as the fruit mature [41]. SISWEET7 $a$ and SISWEET14, which encode membrane localization proteins, are primarily expressed in pedicels, vascular bundles and seeds. The sugar content of tomato fruit in which SISWEET7a or SISWEET14 have been silenced increased significantly, and the size of fruit also increased [85]. Artificial domestication selection of these genes is expected to breed high-quality varieties. These data indicate that SWEET may be involved in the transportation and distribution of soluble sugar in fruit, which has a significant impact on their yield and quality. 


\subsection{Participation in Nectar Secretion}

Nectaries can secrete nectar, which can lure insects to collect nectar to complete the pollination process, thereby ensuring that plants obtain heterologous genes and ensuring population reproduction and evolution. Although the function and composition of nectar have been clearly understood, the mechanism of nectar secretion was unclear before the discovery of the SWEET gene family. The NEC1 (a homolog of AtSWEET9) gene is primarily expressed in the nectary parenchyma cells in Petunia hybrida, and its expression positively correlates with the amount of nectar secreted [63]. Silencing the expression of NEC1 leads to male sterility [64], but to our knowledge, such studies on the nectar phenotype have not been conducted. Lin et al. [86] found that A. thaliana AtSWEET9 is located in the plasma membrane and specifically expressed in nectary parenchyma cells. The amount of nectar secreted by the atsweet 9 mutant is reduced, which clearly shows that AtSWEET9 plays an important role in the secretion of nectar from nectaries [86]. Homologs of AtSWEET9 have been identified in turnip (Brassica rapa) and coyote tobacco (N. attenuata). Suppressing the expression of BrSWEET9 or NaSWEET9 also resulted in a decrease in the secretion of nectar by mutant plants, indicating that these two genes may also play a key role in the secretion of nectar [86].

\subsection{Participation in Leaf Senescence}

The SWEET gene family in plants is also involved in the regulation of the process of senescence. Rice OsSWEET5 can transport galactose and is expressed in senescent leaves. The overexpression of this gene causes significant changes in the contents of soluble sugar and indole acetic acid (IAA) in plant leaves, leading to delayed growth and premature senescence in the seedling stage, indicating that the mediation of transport of galactose by OsSWEET5 plays an important role in plants [87]. However, the OsSWEET5 gene knockouts did not exhibit any phenotypic changes [87]. This finding indicates that there may be other SWEET genes that can transport galactose that are redundant with OsSWEET5. The level of expression of AtSWEET15 in A. thaliana is similar to that of OsSWEET5 and gradually increases during leaf senescence. Plants that overexpressed AtSWEET15 exhibited a phenotype of delayed growth and accelerated leaf senescence, but the T-DNA insertion mutant of AtSWEET15 did not differ significantly from that of the wild-type plants [88,89]. PbSWEET4 of pear (Pyrus bretschneideri), which is homologous to AtSWEET15 of A. thaliana, has been shown to regulate senescence and the content of leaf sugar and is highly expressed in old leaves. The overexpression of PbSWEET4 in strawberries (Fragaria $\times$ ananassa) can reduce the contents of sugar and chlorophyll in leaves and accelerate the senescence of leaves [90]. These studies on the overexpression of certain SWEET genes suggest that this change may disrupt the correct distribution and flow of soluble sugar or cause soluble sugar extravasation, which will negatively affect plant growth.

\section{SWEETs Participate in the Interaction between Host Plants and Pathogens}

The SWEET gene family plays a key role in plant-pathogen interactions [91-95]. When bacterial or fungal pathogens invade plants, they secrete virulence proteins, described as transcription activator-like (TAL) effectors that can bind to the promoters of specific SWEET genes and activate their expression, which helps the pathogens to obtain sugars from plants for their growth and reproduction (Figure 4). Rice OsSWEET11-15 has been proven to provide nutrition for rice bacterial blight (Xanthomonas oryzae pv. oryzae) [68,93,95-101]. $X$. pv. oryzae infects rice and secretes specific TAL effectors, which combine with the specific elements (effector-binding elements, EBEs) of the promoter of the target OsSWEET gene to induce the up-regulated expression of the gene. This leads to the outflow of more carbohydrates so that the pathogenic bacteria can obtain nutrition and multiply. This increases the susceptibility of the plant to disease. TAL effectors that can induce the expression of OsSWEET11-15 have been identified. Among them, four TAL effectors have been identified that can induce the expression of OsSWEET14 [93,95-98]. After suppressing 
OsSWEET11, the rice plants were resistant to sheath blight disease caused by the fungus Rhizoctonia solani [102].

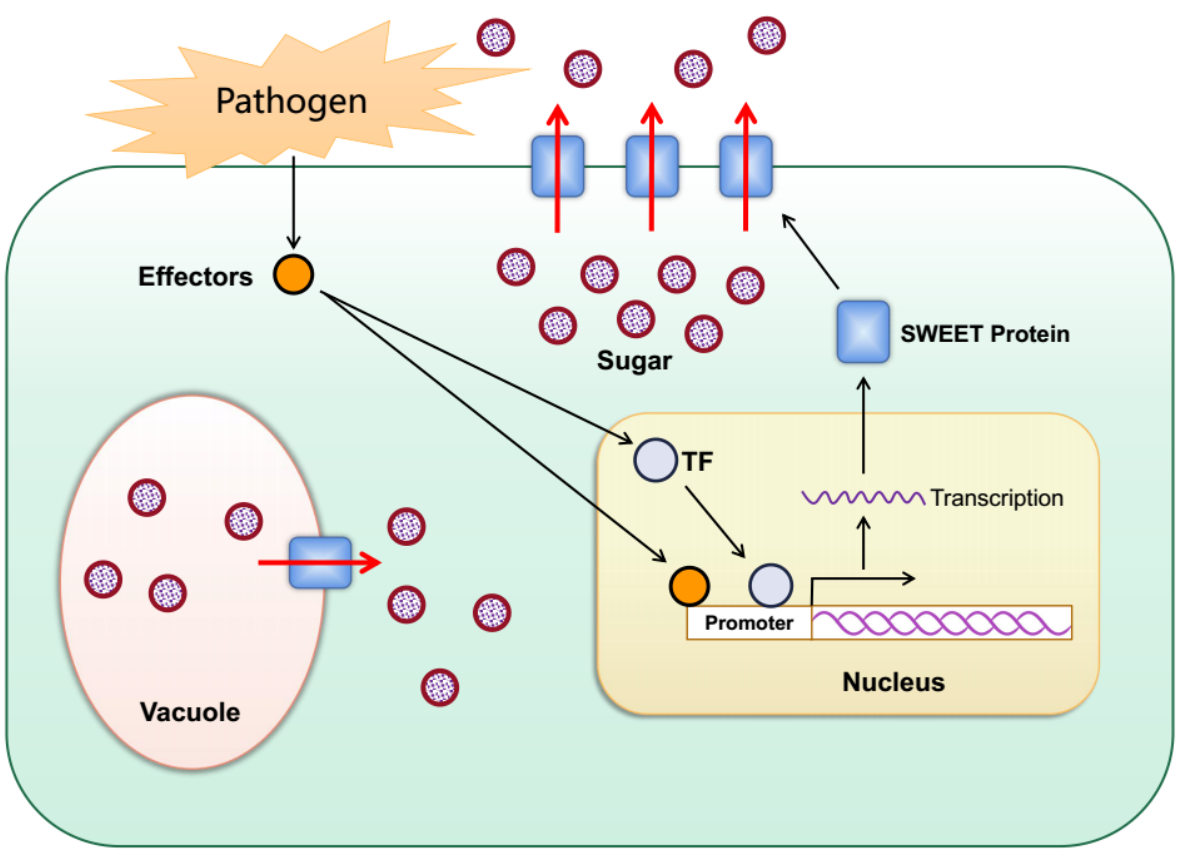

Figure 4. Schematic diagram for the role of plant SWEETs in pathogen nutrition. When bacterial or fungal pathogens invade plants, they secrete TAL effectors into host plant cells. The TAL effectors induce the expression of plant SWEETs either directly or indirectly through activation of transcription factors, resulting in the outflow of sugar into the apoplast as a source of nutrition for the pathogens.

The phenomenon of pathogen-induced SWEET gene expression is also found in other plant species. Cassava (Manihot esculenta) MeSWEET10a can be induced by the TAL20 effector of X. axonopodis pv. Manihotis [103]. Orange CSSWEET1 can be induced by the PthA4 and PthAw effectors of bacterial citrus canker (X. citri ssp. citri) [104]. Grape VvSWEET4 and VvSWEET7 can interact with gray mold (Botrytis cinerea) $[40,105]$. The level of expression of VvSWEET4 and VvSWEET7 was up-regulated after B. cinerea infected grapes [35,93]. The atsweet 4 mutant is not sensitive to B. cinerea [40]. The level of expression of AtSWEET2 increases sharply after the oomycete Pythium irregulare infects the roots of $A$. thaliana, while the atsweet 2 mutant is not sensitive to Pythium [45]. This suggests that the location of AtSWEET2 in the vacuole membrane enables it to provide glucose that Pythium can use to grow and reproduce. The accumulation of sugar in the leaves of $A$. thaliana sweet11;sweet12 double mutants can trigger a defense pathway against the fungal pathogen Colletotrichum higginsianum mediated by salicylic acid [106]. The AtSWEET genes in A. thaliana are also induced by bacterial speck disease (Pseudomonas syringae pv. tomato DC3000), powdery mildew (Golovinomyces cichoracearum) and clubroot (Plasmodiophora brassicae) [35,107]. The level of expression of the SWEET gene (UPA16) in pepper (Capsicum annuum) is induced by black rot (X. campestris pv. vesicatoria) [108]. The level of expression of the SWEET gene in wheat is induced by the rust fungus Puccinia striiformis [109]. GhSWEET10 in cotton (Gossypium hirsutus) can be induced by Avrb6, a TAL effector that determines the pathogenicity of X. citri subsp. malvacearum (Xcm) [110]. Silencing GhSWEET10 reduces the susceptibility of cotton to Xcm [110]. The infection of P. brassicae on B. rapa can induce the translocation of sugar between the tissues that produce sugar and that of the susceptible clubbed tissue. BrSWEETs participate in this process [111]. Unlike the above cases, IbSWEET10 in sweet potato (Ipomoea batatas) plays a positive role in resistance to the fungus Fusarium oxysporum. The overexpression of IbSWEET10 can increase the resistance of sweet potato to F. oxysporum by reducing the sugar content of sweet potato [112]. 
The results described above indicate that the SWEET gene family participates in hostpathogen interactions, but only a few SWEET genes and mechanisms of their interaction with pathogens have been explained. Elucidating these mechanisms will help researchers to modify the binding sites of pathogens through molecular biological methods to obtain crops that are resistant to pathogens. A number of bioinformatics tools, such as PrediTALE, Storyteller, Talvez, TALgetter and Target Finder, can be used to identify and predict EBEs for almost all known TAL effectors [113]. Resistant plants can be obtained by modifying EBEs using gene-editing technology. For example, The CRISPR-Cas9 system was used to edit the EBEs in the promoter regions of SWEET11, SWEET13 and SWEET14, resulting in rice plants that were resistant to the main pathogens that cause rice blight [114]. In this regard, we systematically summarize a strategy to obtain disease-resistant plants by modifying SWEET genes (Figure 5). Moreover, some studies have shown that SWEET family genes not only provide carbohydrates for pathogenic bacteria but also provide nutrients for beneficial microorganisms. For example, alfalfa MtSWEET11 can be induced by rhizobia to provide carbohydrates for the formation of symbiotic nodules [62].

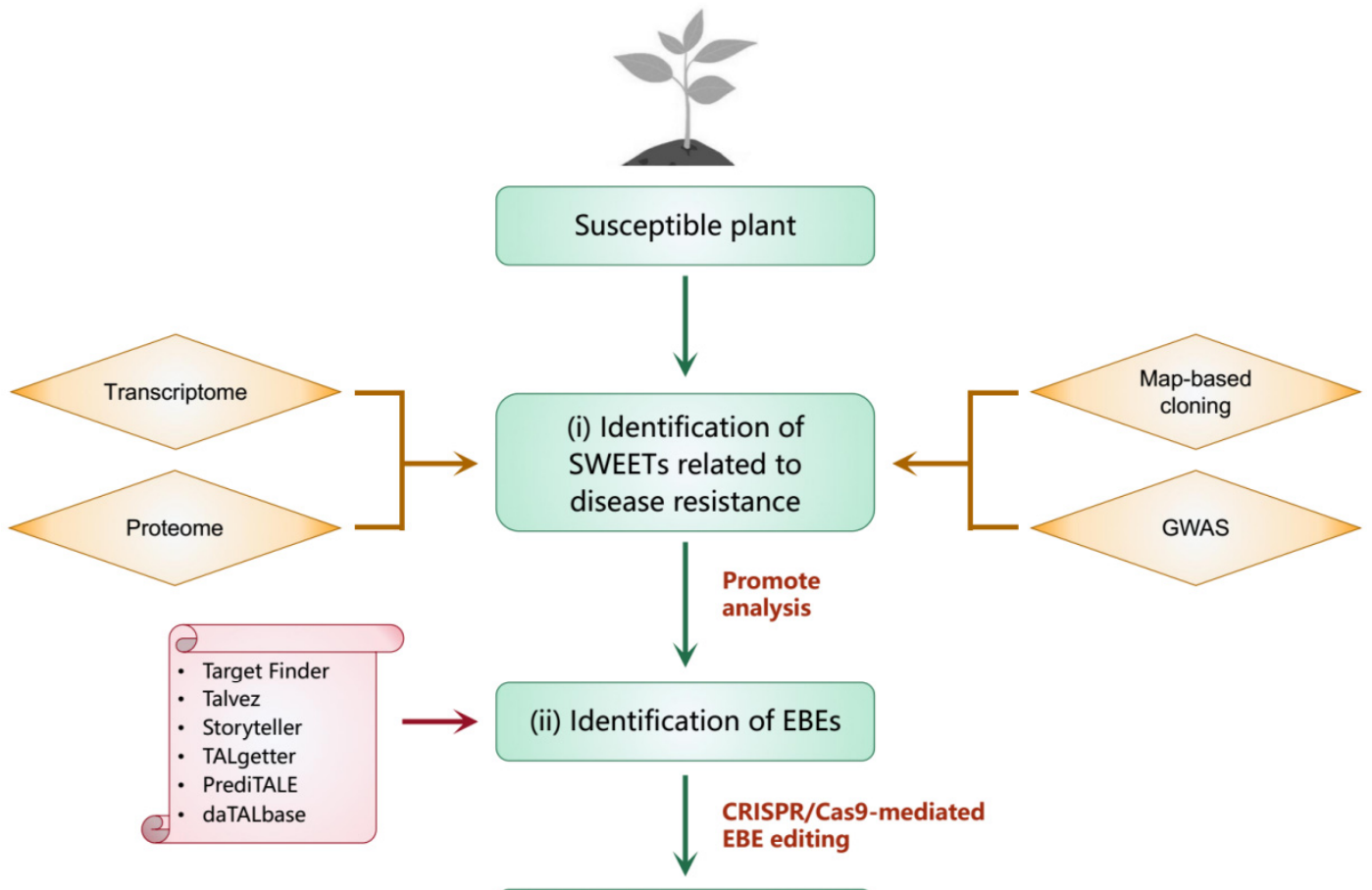

(iii) EBE mutation

(iv) Disease-resistant plant

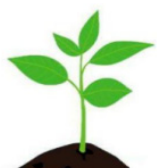

Figure 5. The strategy to obtain disease-resistant plants by modifying SWEET genes. It mainly includes the following steps (i-iv). (i) Identify SWEETs related to disease resistance through methods such as map-based cloning, genome-wide association analysis (GWAS), transcriptome and proteome. (ii) Identify and predict EBEs through tools such as PrediTALE, Storyteller, Talvez, TALgetter and Target Finder. (iii) Modify EBEs using gene-editing technology such as CRISPR-Cas9 system. (iv) Disease resistance test and obtain disease-resistant plants. 


\section{SWEETs Are Involved in Plant Responses to Stress}

Soluble sugar is an important source of energy and material in cells and plays an important role in the regulation of stress responses. Plants that are subjected to stress maintain the balance of cell osmotic potential by regulating the redistribution of soluble sugars in the tissues to help the plants maintain normal growth [115]. Sugar transporters are key factors that regulate the redistribution of soluble sugars, which can respond to a variety of stresses. During the natural cold acclimation process of tea tree (Camellia sinensis), the levels of expression of CSSWEET2, CSSWEET3 and CSSWEET16 were significantly suppressed, while the levels of expression of CSSWEET1 and CSSWEET17 increased sharply [116]. CsSWEET16, which is located in the vacuole membrane, can regulate the tolerance of plants to cold. The overexpression of CSSWEET16 in A. thaliana resulted in plants that were less damaged by cold stress [117]. Several cis-acting elements related to stress and hormone responses were identified in the upstream promoter region of the tomato SISWEET gene. The expression of multiple SISWEET genes in the leaves, roots and fruit at the green and red maturity stage changed significantly when the plants were subjected to high sugar, high salt and high/low temperatures [41]. An expression analysis showed that the banana (Musa spp.) MaSWEETs could be involved in cold, salt and osmotic stress [118]. Cabbage BoSWEETs have been found to be involved in the improvement of tolerance to cold stress [119].

The response of AtSWEET genes to abiotic stress in A. thaliana has been studied indepth. AtSWEET16 and AtSWEET17 are homologs, and both are involved in the responses to abiotic stress. The content of fructose in the leaves of the atsweet 17 mutant plants increased significantly when the plants were subjected to stress from low nitrogen and cold, and the growth of roots was significantly reduced $[46,120]$. Under cold stress conditions, the content of fructose in the leaves of plants that overexpressed AtSWEET17 decreased by $80 \%$, but the root growth increased significantly $[46,120]$. These results indicate that AtSWEET17 is responsible for the two-way transport of fructose to maintain the balance of fructose in the cytoplasm of $A$. thaliana leaves and roots to improve the plant's tolerance to abiotic stresses, such as low nitrogen and cold stress. Chilling injury, osmotic stress and low nitrogen can all cause a decrease in the level of expression of AtSWEET16 [47]. The overexpression of AtSWEET16 caused the soluble sugar content in the plant to differ substantially from that of the wild-type plant, and the rate of seed germination and tolerance to cold increased [47]. The efficiency of growth and nitrogen utilization in plants that overexpressed AtSWEET16 was higher than that of the wild type when the plants had a sufficient supply of nitrogen. However, the wild type could more effectively utilize nitrogen compared with the overexpression plants subjected to low-nitrogen stress [47]. These results indicate that AtSWEET16 is involved in a variety of abiotic stresses, and its function in these abiotic stresses may be relatively independent. The expression level of AtSWEET15 of A. thaliana gradually increased during the natural senescence of leaves. Low temperature, drought and high-salt stress can all induce the expression of AtSWEET15. The induced expression under this osmotic stress depends on the abscisic acid pathway $[88,89,121]$. The tolerance of atsweet 15 mutant plants to high-salt stress was significantly higher than that of the wild-type plants [89]. The overexpression of AtSWEET15 not only accelerated the senescence of plant leaves but also increased their sensitivity to salt stress [89]. This could be owing to the decrease in root cell viability of the transgenic plants caused by the overexpression of AtSWEET15.

AtSWEET11 and AtSWEET12 do not only transport sucrose in the leaves; they also exist in the xylem vessels of flower stems, and they can transport sucrose, glucose and fructose [48]. The stem diameter, stem phloem and xylem area of the atsweet11;12 double mutant plants were significantly reduced under low-temperature stress [48]. However, the low tolerance of double mutant plants to temperature improved significantly [48]. These results indicate that AtSWEET11 and AtSWEET12 can transport sugar to the secondary xylem to meet the nutrients required for the formation of secondary cell walls, thereby regulating the tolerance of $A$. thaliana to low-temperature stress [48]. The levels of expression of 
AtSWEET11 and AtSWEET12 are also regulated by water stress [122]. The levels of expression of the three genes AtSWEET11, AtSWEET12 and AtSUC2 that are involved in sucrose phloem loading in the leaves of $A$. thaliana increased under water deficit conditions, and the ability to transport sucrose from the leaves to the roots increased [122]. Simultaneously, the levels of expression of AtSUC2 and AtSWEET11-15 in the roots increased [122]. This reveals that these genes may function to unload sucrose from the phloem in roots. These results indicate that plants regulate the redistribution of carbohydrates in their tissues by regulating the expression of sucrose carrier protein under water-deficit stress. In other words, more carbohydrates that are synthesized in the leaves are distributed to the root system, thereby reducing the adverse effect of a water deficit on plants.

\section{The Role of SWEETs in Plant Ion Transport}

The SWEET gene family in plants also plays an important role in ion transport. A. thaliana roots were treated with $25 \mu \mathrm{mol} / \mathrm{L}$ aluminum ion [123]. This resulted in the up-regulation of the expression of AtSWEET13 by nearly 160 -fold, indicating that this gene may play an important role in maintaining the content of aluminum in the roots [123]. After soybean seedlings were treated with iron deficiency for $1 \mathrm{~h}$, the level of expression of Glyma05g38351 (the homologous gene of AtSWEET12) in the leaves increased by approximately 3-fold, while the expression level of the Glyma05g38340 and Glyma08g01310 genes that are homologous to AtSWEET13 decreased, indicating that these three SWEET genes may be involved in the transport and distribution of iron in soybeans [124]. Barley (Hordeum vulgare) seedlings were treated with ammonium nitrogen $\left(\mathrm{NH}_{4}{ }^{+}\right)$or nitrate nitrogen $\left(\mathrm{NO}_{3}{ }^{-}\right)$. The level of expression of a SWEET gene that is homologous to AtSWEET11 in the plants treated with ammonium nitrogen was twice that of the plants treated with nitrate nitrogen [125]. This indicates that the gene may play an important role in regulating the transport of nitrogen between cells. During the formation of a symbiotic nodule of the legume M. truncatula, boron deficiency will lead to a decrease in the level of expression of the SWEET gene family. However, when calcium ions are provided to the plant, the expression levels of these down-regulated SWEET genes rapidly recover, indicating that the SWEET gene family may play an important role in the balance of calcium/boron ions [126].

The function of SWEETs in the transport of copper ions has been thoroughly studied. Yuan et al. [69] used the conserved domain of the rice OsSWEET11 as bait to screen the two copper transporters COPT1 and COPT5 located on the plasma membrane using a yeast two-hybrid system. The yeast mutant strain MPY17 has a deletion in the copper ionophore function. Only the simultaneous expression of OSSWEET11, COPT1 and COPT5 can restore the function of yeast to transport copper [69]. This indicates that the three proteins interact to form a copper ion transporter complex on the cell membrane, which performs its function of transporting extracellular copper ions into the cell. The overexpression of OsSWEET11, COPT1 and COPT5 in rice resulted in an increase in the content of copper ions in the aboveground tissues and roots but a decrease in the content of copper ions in the xylem sap [69]. This indicates that OsSWEET11 can affect the redistribution of copper ions in rice and regulate the transport of copper ions.

\section{Conclusions and Future Perspectives}

The transportation and distribution of sugar play important roles in regulating plant growth and development and responding to biotic and abiotic stresses. Therefore, it is particularly necessary to study how sugar transporters transport and redistribute sugar in various stages of plant growth. In the past ten years, there have been many important advances in the research of SWEET proteins, but there are still many problems that have not been resolved. The function of the plant SWEET gene family is closely related to its structure. However, the three-dimensional structures of only two plant SWEET proteins have been resolved to date, and only one conformation that opens into the cell has been observed. The three conformations of the same SWEET protein have not been observed in the same species. These results are not enough to fully understand the mechanism that SWEET 
proteins use to transport sugar. Therefore, further strengthening the crystal structure analysis of SWEET proteins with different sugar transport functions will help to clarify how multiple SWEETs in plants distinguish and recognize their respective substrates and the key factors that promote the conversion between different conformations. Most plants contain multiple members of the SWEET gene family. How these genes work together, how they are regulated, whether they are regulated at the transcriptional or translational level and how they achieve functional diversification still remain unclear. In addition, although SWEET genes have been found in most plants, the functional research on the SWEET gene is primarily focused on $A$. thaliana and rice, while the functional research on other crops needs to be strengthened to fully reveal the diversified functions of SWEET genes.

Research on SWEET sugar transporters in the past decade has shown that SWEETs are involved in important physiological processes, such as plant phloem loading, pollen development, nectar secretion, seed filling, leaf senescence and fruit development. They also play key roles in host-pathogen interactions and various responses to abiotic stress. The use of molecular methods and technologies to regulate the expression of SWEET genes and artificially control the flow of carbohydrates has a substantial potential to improve crop yields, quality and breed varieties that are resistant to disease and stress. Such research will be of substantial value to enable stakeholders to respond to the global food crisis.

Author Contributions: Conceptualization, J.J. and L.Y.; writing-original draft preparation, J.J.; writing-review and editing, J.J., L.Y., Z.F., Y.Z., M.Z., H.L. and Y.W. All authors have read and agreed to the published version of the manuscript.

Funding: This work was funded by the National Natural Science Foundation of China (32002034), the Science and Technology Innovation Program of the Chinese Academy of Agricultural Sciences (CAASASTIP-2013-IVFCAAS), the China Agriculture Research System of MOF and MARA (CARS-23).

Institutional Review Board Statement: Not applicable.

Informed Consent Statement: Not applicable.

Data Availability Statement: Not applicable.

Acknowledgments: We acknowledge all the members of the research group for their helpful comments and inspiration.

Conflicts of Interest: The authors declare no conflict of interest.

\section{References}

1. Lalonde, S.; Wipf, D.; Frommer, W.B. Transport mechanisms for organic forms of carbon and nitrogen between source and sink. Annu. Rev. Plant Biol. 2004, 55, 341-372. [CrossRef] [PubMed]

2. Rolland, F.; Baena-Gonzalez, E.; Sheen, J. Sugar sensing and signaling in plants: Conserved and novel mechanisms. Annu. Rev. Plant Biol. 2006, 57, 675-709. [CrossRef] [PubMed]

3. Nagele, T.; Henkel, S.; Hormiller, I.; Sauter, T.; Sawodny, O.; Ederer, M.; Heyer, A.G. Mathematical modeling of the central carbohydrate metabolism in Arabidopsis reveals a substantial regulatory influence of vacuolar invertase on whole plant carbon metabolism. Plant Physiol. 2010, 153, 260-272. [CrossRef] [PubMed]

4. Lemoine, R.; La Camera, S.; Atanassova, R.; Dedaldechamp, F.; Allario, T.; Pourtau, N.; Bonnemain, J.L.; Laloi, M.; CoutosThevenot, P.; Maurousset, L.; et al. Source-to-sink transport of sugar and regulation by environmental factors. Front. Plant Sci. 2013, 4, 272. [CrossRef] [PubMed]

5. Chen, L.Q.; Cheung, L.S.; Feng, L.; Tanner, W.; Frommer, W.B. Transport of sugars. Annu. Rev. Biochem. 2015, 84, 865-894. [CrossRef] [PubMed]

6. Chen, L.; Qu, X.; Hou, B.; Sosso, D.; Osorio, S.; Fernie, A.R.; Frommer, W.B. Sucrose efflux mediated by SWEET proteins as a key step for phloem transport. Science 2012, 335, 207-211. [CrossRef]

7. Ruan, Y. Sucrose metabolism: Gateway to diverse carbon use and sugar signaling. Annu. Rev. Plant Biol. 2014, 65, 33-67. [CrossRef]

8. Rolland, F.; Moore, B.; Sheen, J. Sugar sensing and signaling in plants. Plant Cell 2002, 14, S185-S205. [CrossRef]

9. Wang, M.; Zang, L.; Jiao, F.; Perez-Garcia, M.D.; Ogé, L.; Hamama, L.; Le Gourrierec, J.; Sakr, S.; Chen, J. Sugar signaling and post-transcriptional regulation in plants: An overlooked or an emerging topic? Front. Plant Sci. 2020, 11, 578096. [CrossRef]

10. Bermejo, C.; Haerizadeh, F.; Takanaga, H.; Chermak, D.; Frommer, W.B. Optical sensors for measuring dynamic changes of cytosolic metabolite levels in yeast. Nat. Protoc. 2011, 6, 1806-1817. [CrossRef] 
11. Roitsch, T. Source-sink regulation by sugar and stress. Curr. Opin. Plant Biol. 1999, 2, 198-206. [CrossRef]

12. Sheen, J. C4 GENE EXPRESSION. Annu. Rev. Plant Biol. 1999, 50, 187-217. [CrossRef] [PubMed]

13. Smeekens, S. Sugar-induced signal transduction in plants. Annu. Rev. Plant Biol. 2000, 51, 49-81. [CrossRef] [PubMed]

14. Gazzarrini, S.; Mccourt, P. Genetic interactions between ABA, ethylene and sugar signaling pathways. Curr. Opin. Plant Biol. 2001, 4, 387-391. [CrossRef]

15. Finkelstein, R.R.; Gibson, S.I. ABA and sugar interactions regulating development: Cross-talk or voices in a crowd? Curr. Opin. Plant Biol. 2002, 5, 26-32. [CrossRef]

16. Kruckeberg, A.L.; Neuhaus, H.E.; Feil, R.; Gottlieb, L.D.; Stitt, M. Decreased-activity mutants of phosphoglucose isomerase in the cytosol and chloroplast of Clarkia Xantiana. Impact on mass-action ratios and fluxes to sucrose and starch, and estimation of flux control coefficients and elasticity coefficients. Biochem. J. 1989, 261, 457-467. [CrossRef]

17. Neuhaus, H.E.; Quick, W.P.; Siegl, G.; Stitt, M. Control of photosynthate partitioning in spinach leaves: Analysis of the interaction between feedforward and feedback regulation of sucrose synthesis. Planta 1990, 181, 583-592. [CrossRef]

18. Flugge, U.I. Phosphate translocators in plastids. Annu. Rev. Plant Phys. 1999, 50, 27-45. [CrossRef]

19. Fettke, J.; Eckermann, N.; Tiessen, A.; Geigenberger, P.; Steup, M. Identification, subcellular localization and biochemical characterization of water-soluble heteroglycans (SHG) in leaves of Arabidopsis thaliana L.: Distinct SHG reside in the cytosol and in the apoplast. Plant J. 2005, 43, 568-585. [CrossRef]

20. Smith, A.M.; Stitt, M. Coordination of carbon supply and plant growth. Plant Cell Environ. 2007, 30, 1126-1149. [CrossRef]

21. Roitsch, T.; Gonzalez, M.C. Function and regulation of plant invertases: Sweet sensations. Trends Plant Sci. 2004, 9, 606-613. [CrossRef] [PubMed]

22. Stein, O.; Granot, D. An overview of sucrose synthases in plants. Front. Plant Sci. 2019, 10, 95. [CrossRef] [PubMed]

23. Riesmeier, J.W.; Willmitzer, L.; Frommer, W.B. Isolation and characterization of a sucrose carrier c DNA from spinach by functional expression in yeast. EMBO J. 1992, 11, 4705-4713. [CrossRef] [PubMed]

24. Lemoine, R. Sucrose transporters in plants: Update on function and structure. BBA-Biomembr. 2000, 1465, 246-262. [CrossRef]

25. Ruiz-Medrano, R.; Xoconostle-Cazares, B.; Lucas, W.J. The phloem as a conduit for inter-organ communication. Curr. Opin. Plant Biol. 2001, 4, 202-209. [CrossRef]

26. Sauer, N. Molecular physiology of higher plant sucrose transporters. FEBS Lett. 2007, 581, 2309-2317. [CrossRef]

27. Kühn, C.; Grof, C.P. Sucrose transporters of higher plants. Curr. Opin. Plant Biol. 2010, 13, 288-298. [CrossRef]

28. Geiger, D. Plant sucrose transporters from a biophysical point of view. Mol. Plant 2011, 4, 395-406. [CrossRef]

29. Schneider, S.; Hulpke, S.; Schulz, A.; Yaron, I.; Holl, J.; Imlau, A.; Schmitt, B.; Batz, S.; Wolf, S.; Hedrich, R.; et al. Vacuoles release sucrose via tonoplast-localised SUC4-type transporters. Plant Biol. 2012, 14, 325-336. [CrossRef]

30. Maynard, J.W.; Lucas, W.J. Sucrose and glucose uptake into Beta vulgaris leaf tissues: A case for general (Apoplastic) retrieval systems. Plant Physiol. 1982, 70, 1436-1443. [CrossRef]

31. Baker, R.F.; Leach, K.A.; Braun, D.M. SWEET as sugar: New sucrose effluxers in plants. Mol. Plant 2012, 5, 766-768. [CrossRef] [PubMed]

32. Jeena, G.S.; Kumar, S.; Shukla, R.K. Structure, evolution and diverse physiological roles of SWEET sugar transporters in plants. Plant Mol. Biol. 2019, 100, 351-365. [CrossRef] [PubMed]

33. Anjali, A.; Fatima, U.; Manu, M.S.; Ramasamy, S.; Senthil-Kumar, M. Structure and regulation of SWEET transporters in plants: An update. Plant Physiol. Biochem. 2020, 156, 1-6. [CrossRef] [PubMed]

34. Looger, L.L.; Lalonde, S.; Frommer, W.B. Genetically encoded FRET sensors for visualizing metabolites with subcellular resolution in living cells. Plant Physiol. 2005, 138, 555-557. [CrossRef]

35. Chen, L.; Hou, B.H.; Lalonde, S.; Takanaga, H.; Hartung, M.L.; Quet, X.Q.; Guo, W.-J.; Kim, J.-G.; Underwood, W.; Chaudhuri, B.; et al. Sugar transporters for intercellular exchange and nutrition of pathogens. Nature 2010, 468, 527-532. [CrossRef]

36. Ayre, B.G. Membrane-transport systems for sucrose in relation to whole-plant carbon partitioning. Mol. Plant 2011, 4, 377-394. [CrossRef]

37. Slewinski, T.L. Diverse functional roles of monosaccharide transporters and their homologs in vascular plants: A physiological perspective. Mol. Plant 2011, 4, 641-662. [CrossRef]

38. Yuan, M.; Wang, S. Rice MtN3/saliva/SWEET family genes and their homologs in cellular organisms. Mol. Plant 2013, 6, 665-674 [CrossRef]

39. Patil, G.; Valliyodan, B.; Deshmukh, R.; Prince, S.; Nicander, B.; Zhao, M.; Sonah, H.; Song, L.; Lin, L.; Chaudhary, J.; et al. Soybean (Glycine max) SWEET gene family: Insights through comparative genomics, transcriptome profiling and whole genome re-sequence analysis. BMC Genom. 2015, 16, 520. [CrossRef]

40. Chong, J.; Piron, M.C.; Meyer, S.; Merdinoglu, D.; Bertsch, C.; Mestre, P. The SWEET family of sugar transporters in grapevine: VvSWEET4 is involved in the interaction with Botrytis cinerea. J. Exp. Bot. 2014, 65, 6589-6601. [CrossRef]

41. Feng, C.; Han, J.; Han, X.; Jiang, J. Genome-wide identification, phylogeny, and expression analysis of the SWEET gene family in tomato. Gene 2015, 573, 261-272. [CrossRef] [PubMed]

42. Sosso, D.; Luo, D.; Li, Q.; Sasse, J.; Yang, J.; Gendrot, G.; Suzuki, M.; Koch, K.E.; Mccarty, D.R.; Chourey, P.S.; et al. Seed filling in domesticated maize and rice depends on SWEET-mediated hexose transport. Nat. Genet. 2015, 47, 1489-1493. [CrossRef] [PubMed] 
43. Zhang, L.; Wang, L.; Zhang, J.; Song, C.; Li, Y.; Li, J.; Lu, M. Expression and localization of SWEETs in Populus and the effect of SWEET7 overexpression in secondary growth. Tree Physiol. 2021, 41, 882-899. [CrossRef] [PubMed]

44. Qin, J.; Jiang, Y.; Lu, Y.; Zhao, P.; Wu, B.; Li, H.; Wang, Y.; Xu, S.; Sun, Q.; Liu, Z. Genome-wide identification and transcriptome profiling reveal great expansion of SWEET gene family and their wide-spread responses to abiotic stress in wheat (Triticum aestivum L.). J. Integr. Agr. 2020, 19, 1704-1720. [CrossRef]

45. Chen, H.; Huh, J.H.; Yu, Y.C.; Ho, L.H.; Chen, L.; Tholl, D.; Frommer, W.B.; Guo, W.J. The Arabidopsis vacuolar sugar transporter SWEET2 limits carbon sequestration from roots and restricts Pythium infection. Plant J. 2015, 83, 1046-1058. [CrossRef] [PubMed]

46. Guo, W.J.; Nagy, R.; Chen, H.Y.; Pfrunder, S.; Yu, Y.C.; Santelia, D.; Frommer, W.B.; Martinoia, E. SWEET17, a facilitative transporter, mediates fructose transport across the tonoplast of Arabidopsis roots and leaves. Plant Physiol. 2014, 164, 777-789. [CrossRef]

47. Klemens, P.A.; Patzke, K.; Deitmer, J.; Spinner, L.; Le Hir, R.; Bellini, C.; Bedu, M.; Chardon, F.; Krapp, A.; Neuhaus, H.E. Overexpression of the vacuolar sugar carrier AtSWEET16 modifies germination, growth, and stress tolerance in Arabidopsis. Plant Physiol. 2013, 163, 1338-1352. [CrossRef]

48. Le Hir, R.; Spinner, L.; Klemens, P.A.; Chakraborti, D.; Marco, F.; Vilaine, F.; Wolff, N.; Lemoine, R.; Porcheron, B.; Géry, C.; et al. Disruption of the sugar transporters AtSWEET11 and AtSWEET12 affects vascular development and freezing tolerance in Arabidopsis. Mol. Plant 2015, 8, 1687-1690. [CrossRef]

49. Büttner, M.; Sauer, N. Monosaccharide transporters in plants: Structure, function and physiology. BBA-Biomembr. 2000, 1465, 263-274. [CrossRef]

50. Hirai, T.; Heymann, J.A.W.; Maloney, P.C.; Subramaniam, S. Structural model for 12-helix transporters belonging to the major facilitator superfamily. J. Bacteriol. 2003, 185, 1712-1718. [CrossRef]

51. Forrest, L.R.; Krämer, R.; Ziegler, C. The structural basis of secondary active transport mechanisms. BBA-Bioenerg. 2011, 1807, 167-188. [CrossRef] [PubMed]

52. Xuan, Y.H.; Hu, Y.B.; Chen, L.Q.; Sosso, D.; Ducat, D.C.; Hou, B.H.; Frommer, W.B. Functional role of oligomerization for bacterial and plant SWEET sugar transporter family. Proc. Natl. Acad. Sci. USA 2013, 110, E3685-E3694. [CrossRef] [PubMed]

53. Xu, Y.; Tao, Y.; Cheung, L.S.; Fan, C.; Chen, L.Q.; Xu, S.; Perry, K.; Frommer, W.B.; Feng, L. Structures of bacterial homologues of SWEET transporters in two distinct conformations. Nature 2014, 515, 448-452. [CrossRef] [PubMed]

54. Wang, J.; Yan, C.; Li, Y.; Hirata, K.; Yamamoto, M.; Yan, N.; Hu, Q. Crystal structure of a bacterial homologue of SWEET transporters. Cell Res. 2014, 24, 1486-1489. [CrossRef] [PubMed]

55. Lee, Y.; Nishizawa, T.; Yamashita, K.; Ishitani, R.; Nureki, O. Structural basis for the facilitative diffusion mechanism by SemiSWEET transporter. Nat. Commun. 2015, 6, 6112. [CrossRef] [PubMed]

56. Feng, L.; Frommer, W.B. Structure and function of SemiSWEET and SWEET sugar transporters. Trends Biochem. Sci. 2015, 40, 480-486. [CrossRef] [PubMed]

57. Tao, Y.; Cheung, L.S.; Li, S.; Eom, J.S.; Chen, L.Q.; Xu, Y.; Perry, K.; Frommer, W.B.; Feng, L. Structure of a eukaryotic SWEET transporter in a homotrimeric complex. Nature 2015, 527, 259-263. [CrossRef]

58. Han, L.; Zhu, Y.; Liu, M.; Zhou, Y.; Lu, G.; Lan, L.; Wang, X.; Zhao, Y.; Zhang, X.C. Molecular mechanism of substrate recognition and transport by the AtSWEET13 sugar transporter. Proc. Natl. Acad. Sci. USA 2017, 114, 10089-10094. [CrossRef]

59. Eom, J.S.; Chen, L.Q.; Sosso, D.; Julius, B.T.; Lin, I.W.; Qu, X.Q.; Braun, D.M.; Frommer, W.B. SWEETs, transporters for intracellular and intercellular sugar translocation. Curr. Opin. Plant Biol. 2015, 25, 53-62. [CrossRef]

60. Rennie, E.A.; Turgeon, R. A comprehensive picture of phloem loading strategies. Proc. Natl. Acad. Sci. USA 2009, 106, 14162-14167. [CrossRef]

61. Chu, Z.; Fu, B.; Yang, H.; Xu, C.; Li, Z.; Sanchez, A.; Park, Y.J.; Bennetzen, J.L.; Zhang, Q.; Wang, S. Targeting xa13, a recessive gene for bacterial blight resistance in rice. Theor. Appl. Genet. 2006, 112, 455-461. [CrossRef] [PubMed]

62. Kryvoruchko, I.S.; Sinharoy, S.; Torres-Jerez, I.; Sosso, D.; Pislariu, C.I.; Guan, D.; Murray, J.; Benedito, V.A.; Frommer, W.B.; Udvardi, M.K. MtSWEET11, a nodule-specifc sucrose transporter of Medicago truncatula. Plant Physiol. 2016, 171, 554-565. [CrossRef] [PubMed]

63. Ge, Y.; Angenent, G.C.; Wittich, P.E.; Peters, J.; Franken, J.; Busscher, M.; Zhang, L.M.; Dahlhaus, E.; Kater, M.M.; Wullems, G.J.; et al. NEC1, a novel gene, highly expressed in nectary tissue of Petunia hybrida. Plant J. 2000, 24, 725-734. [CrossRef] [PubMed]

64. Ge, Y.X.; Angenent, G.C.; Dahlhaus, E.; Franken, J.; Peters, J.; Wullems, G.J.; Creemers-Molenaar, J. Partial silencing of the NEC1 gene results in early opening of anthers in Petunia hybrida. Mol. Genet. Genom. 2001, 265, 414-423. [CrossRef] [PubMed]

65. Guan, Y.; Huang, X.; Zhu, J.; Gao, J.; Zhang, H.; Yang, Z. RUPTURED POLLEN GRAIN1, a member of the MtN3/saliva gene family, is crucial for exine pattern formation and cell integrity of microspores in Arabidopsis. Plant Physiol. 2008, 147, 852-863. [CrossRef]

66. Sun, M.; Huang, X.; Yang, J.; Guan, Y.; Yang, Z. Arabidopsis RPG1 is important for primexine deposition and functions redundantly with RPG2 for plant fertility at the late reproductive stage. Plant Reprod. 2013, 26, 83-91. [CrossRef]

67. Chu, Z.; Yuan, M.; Yao, J.; Ge, X.; Yuan, B.; Xu, C.; Li, X.; Fu, B.; Li, Z.; Bennetzen, J.L.; et al. Promoter mutations of an essential gene for pollen development result in disease resistance in rice. Genes Dev. 2006, 20, 1250-1255. [CrossRef]

68. Yang, B.; Sugio, A.; White, F.F. Os8N3 is a host disease-susceptibility gene for bacterial blight of rice. Proc. Natl. Acad. Sci. USA 2006, 103, 10503-10508. [CrossRef] 
69. Yuan, M.; Chu, Z.; Li, X.; Xu, C.; Wang, S. The bacterial pathogen Xanthomonas oryzae overcomes rice defenses by regulating host copper redistribution. Plant Cell 2010, 22, 3164-3176. [CrossRef]

70. Zheng, Q.; Tang, Z.; Xu, Q.; Deng, X. Isolation, phylogenetic relationship and expression profiling of sugar transporter genes in sweet orange (Citrus sinensis). Plant Cell Tiss. Org. 2014, 119, 609-624. [CrossRef]

71. Salts, Y.; Sobolev, I.; Chmelnitsky, I.; Shabtai, S.; Barg, R. Genomic structure and expression of Lestd1, a seven-transmembranedomain proteonencoding gene specically expressed in tomato pollen. Isr. J. Plant Sci. 2005, 53, 79-88.

72. Jiang, L.; Song, C.; Zhu, X.; Yang, J. SWEET transporters and the potential functions of these sequences in tea (Camellia sinensis) Front. Genet. 2021, 12, 655843. [CrossRef] [PubMed]

73. Xuan, C.; Lan, G.; Si, F.; Zeng, Z.; Wang, C.; Yadav, V.; Wei, C.; Zhang, X. Systematic genome-wide study and expression analysis of SWEET gene family: Sugar transporter family contributes to biotic and abiotic stimuli in watermelon. Int. J. Mol. Sci. 2021, 22, 8407. [CrossRef] [PubMed]

74. Iftikhar, J.; Lyu, M.; Liu, Z.; Mehmood, N.; Munir, N.; Ahmed, M.A.A.; Batool, W.; Aslam, M.M.; Yuan, Y.; Wu, B. Sugar and hormone dynamics and the expression profiles of SUT/SUC and SWEET sugar transporters during flower development in petunia axillaris. Plants 2020, 9, 1770. [CrossRef] [PubMed]

75. Wang, P.; Wei, P.; Niu, F.; Liu, X.; Zhang, H.; Lyu, M.; Yuan, Y.; Wu, B. Cloning and Functional Assessments of Floral-Expressed SWEET Transporter Genes from Jasminum sambac. Int. J. Mol. Sci. 2019, 20, 4001. [CrossRef]

76. Zhou, Y.; Cui, X.; Hu, A.; Miao, Y.; Zhang, L. Characterization and functional analysis of pollen-specific PwSWEET1 in Picea wilsonii. J. For. Res. 2020, 31, 1913-1922. [CrossRef]

77. Wang, E.; Wang, J.; Zhu, X.; Hao, W.; Wang, L.; Li, Q.; Zhang, L.; He, W.; Lu, B.; Lin, H.; et al. Control of rice grain-filling and yield by a gene with a potential signature of domestication. Nat. Genet. 2008, 40, 1370-1374. [CrossRef]

78. Chen, L.Q.; Lin, I.W.; Qu, X.Q.; Sosso, D.; McFarlane, H.E.; Londoño, A.; Samuels, A.L.; Frommer, W.B. A cascade of sequentially expressed sucrose transporters in the seed coat and endosperm provides nutrition for the Arabidopsis embryo. Plant Cell 2015, 27, 607-619. [CrossRef]

79. Ma, L.; Zhang, D.; Miao, Q.; Yang, J.; Xuan, Y.; Hu, Y. Essential role of sugar transporter OsSWEET11 during the early stage of rice grain filling. Plant Cell Physiol. 2017, 58, 863-873. [CrossRef]

80. Yang, J.; Luo, D.; Yang, B.; Frommer, W.B.; Eom, J.S. SWEET11 and 15 as key players in seed filling in rice. New Phytol. 2018, 218 , 604-615. [CrossRef]

81. Fei, H.; Yang, Z.; Lu, Q.; Wen, X.; Zhang, Y.; Zhang, A.; Lu, C. OsSWEET14 cooperates with OsSWEET11 to contribute to grain filling in rice. Plant Sci. 2021, 306, 110851. [CrossRef] [PubMed]

82. Wang, S.; Yokosho, K.; Guo, R.; Whelan, J.; Ruan, Y.; Ma, J.; Shou, H. The soybean sugar transporter Gm SWEET15 mediates sucrose export from endosperm to early embryo. Plant Physiol. 2019, 180, 2133-2141. [CrossRef] [PubMed]

83. Guo, C.; Li, H.; Xia, X.; Liu, X.; Yang, L. Functional and evolution characterization of SWEET sugar transporters in Ananas comosus Biochem. Biophys. Res. Commun. 2018, 496, 407-414. [CrossRef] [PubMed]

84. Zhen, Q.; Fang, T.; Peng, Q.; Liao, L.; Zhao, L.; Owiti, A.; Han, Y. Developing gene-tagged molecular markers for evaluation of genetic association of apple SWEET genes with fruit sugar accumulation. Hortic. Res. 2018, 5, 14. [CrossRef] [PubMed]

85. Zhang, X.; Feng, C.; Wang, M.; Li, T.; Liu, X.; Jiang, J. Plasma membrane-localized SISWEET7a and SISWEET14 regulate sugar transport and storage in tomato fruits. Hortic. Res. 2021, 8, 186. [CrossRef]

86. Lin, I.W.; Sosso, D.; Chen, L.; Gase, K.; Kim, S.; Kessler, D.; Klinkenberg, P.M.; Gorder, M.K.; Hou, B.-H.; Qu, X.-Q.; et al. Nectar secretion requires sucrose phosphate synthases and the sugar transporter SWEET9. Nature 2014, 508, 546-549. [CrossRef]

87. Zhou, Y.; Liu, L.; Huang, W.; Yuan, M.; Zhou, F.; Li, X.; Lin, Y. Overexpression of OsSWEET5 in rice causes growth retardation and precocious senescence. PLoS ONE 2014, 9, e94210. [CrossRef]

88. Quirino, B.F.; Normanly, J.; Amasino, R.M. Diverse range of gene activity during Arabidopsis thaliana leaf senescence includes pathogen-independent induction of defense-related genes. Plant Mol. Biol. 1999, 40, 267-278. [CrossRef]

89. Seo, P.J.; Park, J.M.; Kang, S.K.; Kim, S.G.; Park, C.M. An Arabidopsis senescence- associated protein SAG29 regulates cell viability under high salinity. Planta 2011, 233, 189-200. [CrossRef]

90. Ni, J.; Li, J.; Zhu, R.; Zhang, M.; Wu, J. Overexpression of sugar transporter gene PbSWEET4 of pear causes sugar reduce and early senescence in leaves. Gene 2020, 743, 144582. [CrossRef]

91. Bogdanove, A.J.; Schornack, S.; Lahaye, T. TAL effectors: Finding plant genes for disease and defense. Curr. Opin. Plant Biol. 2010, 13, 394-401. [CrossRef] [PubMed]

92. Muñoz-Bodnar, A.; Bernal, A.; Szurek, B.; López, C.E. Tell me a tale of TALEs. Mol. Biotechnol. 2013, 53, 228-235. [CrossRef] [PubMed]

93. Streubel, J.; Pesce, C.; Hutin, M.; Koebnik, R.; Boch, J.; Szurek, B. Five phylogenetically close rice SWEET genes confer TAL effectormediated susceptibility to Xanthomonas oryzae pv. oryzae. New Phytol. 2013, 200, 808-819. [CrossRef] [PubMed]

94. Verdier, V.; Triplett, L.R.; Hummel, A.W.; Corral, R.; Cernadas, R.A.; Schmidt, C.L.; Bogdanove, A.J.; Leach, J.E. Transcription activator-like (TAL) effectors targeting OsSWEET genes enhance virulence on diverse rice (Oryza sativa) varieties when expressed individually in a TAL effectordeficient strain of Xanthomonas oryzae. New Phytol. 2012, 196, 1197-1207. [CrossRef] [PubMed]

95. Yu, Y.; Streubel, J.; Balzergue, S.; Champion, A.; Boch, J.; Koebnik, R.; Feng, J.; Verdier, V.; Szurek, B. Colonization of rice leaf blades by an African strain of Xanthomonas oryzae pv. oryzae depends on a new TAL effector that induces the rice nodulin-3 Os11N3 gene. Mol. Plant Microbe Interact. 2011, 24, 1102-1113. [CrossRef] 
96. Yang, B.; White, F.F. Diverse members of the AvrBs3/PthA family of type III effectors are major virulence determinants in bacterial blight disease of rice. Mol. Plant Microbe Interact. 2004, 17, 1192-1200. [CrossRef]

97. Antony, G.; Zhou, J.; Huang, S.; Li, T.; Liu, B.; White, F.; Yang, B. Rice xa13 recessive resistance to bacterial blight is defeated by induction of the disease susceptibility gene Os-11N3. Plant Cell 2010, 22, 3864-3876. [CrossRef]

98. Römer, P.; Recht, S.; Strau $\beta$, T.; Elsaesser, J.; Schornack, S.; Boch, J.; Wang, S.; Lahaye, T. Promoter elements of rice susceptibility genes are bound and activated by specific TAL effectors from the bacterial blight pathogen, Xanthomonas oryzae pv. Oryzae. New Phytol. 2010, 187, 1048-1057. [CrossRef]

99. Liu, Q.; Yuan, M.; Zhou, Y.; Li, X.; Xiao, J.; Wang, S. A paralog of the MtN3/saliva family recessively confers race-specific resistance to Xanthomonas oryzae in rice. Plant Cell Environ. 2011, 34, 1958-1969. [CrossRef]

100. Li, T.; Huang, S.; Zhou, J.; Yang, B. Designer TAL effectors induce disease susceptibility and resistance to Xanthomonas oryzae pv. oryzae in rice. Mol. Plant 2013, 6, 781-789. [CrossRef]

101. Zhou, J.; Peng, Z.; Long, J.; Sosso, D.; Liu, B.; Eom, J.; Huang, S.; Liu, S.; Vera Cruz, C.; Frommer, W.B.; et al. Gene targeting by the TAL effector PthXo2 reveals cryptic resistance gene for bacterial blight of rice. Plant J. 2015, 82, 632-643. [CrossRef] [PubMed]

102. Gao, Y.; Zhang, C.; Han, X.; Wang, Z.; Ma, L.; Yuan, D.; Wu, J.N.; Zhu, X.F.; Liu, J.M.; Li, D.P.; et al. Inhibition of OsSWEET11 function in mesophyll cells improves resistance of rice to sheath blight disease. Mol. Plant Pathol. 2018, 19, 2149-2161. [CrossRef] [PubMed]

103. Cohn, M.; Bart, R.S.; Shybut, M.; Dahlbeck, D.; Gomez, M.; Morbitzer, R.; Hou, B.; Frommer, W.B.; Lahaye, T.; Staskawicz, B.J. Xanthomonas axonopodis virulence is promoted by a transcription activator-like effectormediated induction of a SWEET sugar transporter in cassava. Mol. Plant Microbe Interact. 2014, 27, 1186-1198. [CrossRef] [PubMed]

104. Hu, Y.; Zhang, J.; Jia, H.; Sosso, D.; Li, T.; Frommer, W.B.; Yang, B.; Whiteb, F.F.; Wang, N.; Jones, J.B. Lateral organ boundaries 1 is a disease susceptibility gene for citrus bacterial canker disease. Proc. Natl. Acad. Sci. USA 2014, 111, E521-E529. [CrossRef] [PubMed]

105. Breia, R.; Conde, A.; Pimentel, D.; Conde, C.; Fortes, A.M.; Granell, A.; Gerós, H. VvSWEET7 Is a Mono- and Disaccharide Transporter UpRegulated in Response to Botrytis cinerea Infection in Grape Berries. Front. Plant Sci. 2020, 10, 1753. [CrossRef] [PubMed]

106. Pierre, G.; Martin, K.; Timo, E.; Sonnewald, U.; Koch, C.; Voll, L.M. Sugar Accumulation in Leaves of Arabidopsis sweet11/sweet12 Double Mutants Enhances Priming of the Salicylic Acid-Mediated Defense Response. Front. Plant Sci. 2017, 8, 1378.

107. Siemens, J.; Keller, I.; Sarx, J.; Kunz, S.; Schuller, A.; Nagel, W.; Schmülling, T.; Parniske, M.; Ludwig-Müller, J. Transcriptome analysis of Arabidopsis clubroots indicate a key role for cytokinins in disease development. Mol. Plant Microbe Interact. 2006, 19, 480-494. [CrossRef]

108. Kay, S.; Hahn, S.; Marois, E.; Wieduwild, R.; Bonas, U. Detailed analysis of the DNA recognition motifs of the Xanthomonas type III effectors AvrBs3 and AvrBs3 $\Delta$ rep16. Plant J. 2009, 59, 859-871. [CrossRef]

109. Yu, X.; Wang, X.; Wang, C.; Chen, X.; Qu, Z.; Yu, X.; Han, Q.; Jie, Z.; Guo, J.; Huang, L. Wheat defense genes in fungal (Puccinia striiformis) infection. Funct. Integr. Genomic. 2010, 10, 227-239. [CrossRef]

110. Cox, K.L.; Meng, F.; Wilkins, K.E.; Li, F.; Wang, P.; Booher, N.J.; Carpenter, S.C.D.; Chen, L.Q.; Zheng, H.; Gao, X. TAL efector driven induction of a SWEET gene confers susceptibility to bacterial blight of cotton. Nat. Commun. 2017, 8, 15588. [CrossRef]

111. Li, H.; Li, X.; Xuan, Y.; Jiang, J.; Wei, Y.; Piao, Z. Genome wide identifcation and expression profling of SWEET genes family reveals its role during Plasmodiophora brassicae-induced formation of clubroot in Brassica rapa. Front. Plant Sci. 2018, 9, 207. [CrossRef] [PubMed]

112. Li, Y.; Wang, Y.; Zhang, H.; Zhang, Q.; Zhai, H.; Liu, Q.; He, S. The plasma membrane-localized sucrose transporter IbSWEET10 contributes to the resistance of sweet potato to Fusarium oxysporum. Front. Plant Sci. 2017, 14, 197. [CrossRef] [PubMed]

113. Erkes, A.; Mücke, S.; Reschke, M.; Boch, J.; Grau, J. PrediTALE: A novel model learned from quantitative data allows for new perspectives on TALE targeting. PLoS Comput. Biol. 2019, 15, e1007206. [CrossRef] [PubMed]

114. Oliva, R.; Ji, C.; Atienza-Grande, G.; Huguet-Tapia, J.C.; Perez-Quintero, A.; Li, T.; Eom, J.-S.; Li, C.; Nguyen, H.; Liu, B.; et al Broad-spectrum resistance to bacterial blight in rice using genome editing. Nat. Biotechnol. 2019, 37, 1344-1350. [CrossRef]

115. Yamada, K.; Osakabe, Y.; Mizoi, J.; Nakashima, K.; Fujita, Y.; Shinozaki, K.; Yamaguchi-Shinozaki, K. Functional analysis of an Arabidopsis thaliana abiotic stress-inducible facilitated diffusion transporter for monosaccharides. J. Biol. Chem. 2010, 285, 1138-1146. [CrossRef]

116. Yue, C.; Cao, H.; Wang, L.; Zhou, Y.; Huang, Y.; Hao, X.; Wang, Y.; Wang, B.; Yang, Y.; Wang, X. Effects of cold acclimation on sugar metabolism and sugar-related gene expression in tea plant during the winter season. Plant Mol. Biol. 2015, 88, 591-608. [CrossRef]

117. Wang, L.; Yao, L.; Hao, X.; Li, N.; Qian, W.; Yue, C.; Ding, C.; Zeng, J.; Yang, Y.; Wang, X. Tea plant SWEET transporters: Expression profiling, sugar transport, and the involvement of CsSWEET16 in modifying cold tolerance in Arabidopsis. Plant Mol. Biol. 2018, 96, 577-592. [CrossRef]

118. Miao, H.; Sun, P.; Liu, Q.; Miao, Y.; Liu, J.; Zhang, K.; Hu, W.; Zhang, J.; Wang, J.; Wang, Z.; et al. Genomewide analyses of SWEET family proteins reveal involvement in fruit development and abiotic/biotic stress responses in banana. Sci. Rep. 2017, 7, 3536. [CrossRef]

119. Zhang, W.; Wang, S.; Yu, F.; Tang, J.; Shan, X.; Bao, K.; Yu, L.; Wang, H.; Fei, Z.; Li, J. Genome-wide characterization and expression profling of SWEET genes in cabbage (Brassica oleracea var. capitata L.) reveal their roles in chilling and clubroot disease responses. BMC Genom. 2019, 20, 93. 
120. Chardon, F.; Bedu, M.; Calenge, F.; Klemens, P.A.W.; Spinner, L.; Clement, G.; Chietera, G.; Léran, S.; Ferrand, M.; Lacombe, B.; et al. Leaf fructose content is controlled by the vacuolar transporter SWEET17 in Arabidopsis. Curr. Biol. 2013, 23, 697-702. [CrossRef]

121. He, F.; Kang, J.; Zhou, X.; Su, Z.; Qu, L.; Gu, H. Variation at the transcriptional level among Chinese natural populations of Arabidopsis thaliana in response to cold stress. Chin. Sci. Bull 2008, 53, 2989-2999. [CrossRef]

122. Durand, M.; Porcheron, B.; Hennion, N.; Maurousset, L.; Lemoine, R. Water deficit enhances C export to the roots in Arabidopsis thaliana plants with contribution of sucrose transporters in both shoot and roots. Plant Physiol. 2016, 170, 1460-1479. [CrossRef] [PubMed]

123. Zhao, C.; Ikka, T.; Sawaki, Y.; Kobayashi, Y.; Suzuki, Y.; Hibino, T.; Sato, S.; Sakurai, N.; Shibata, D.; Koyama, H. Comparative transcriptomic characterization of aluminum, sodium chloride, cadmium and copper rhizotoxicities in Arabidopsis thaliana. BMC Plant Biol. 2009, 9, 32. [CrossRef]

124. Lauter, A.N.M.; Peiffer, G.A.; Yin, T.; Whitham, S.A.; Cook, D.; Shoemaker, R.C.; Graham, M.A. Identification of candidate genes involved in early iron deficiency chlorosis signaling in soybean (Glycine max) roots and leaves. BMC Genom. 2014, 15, 702.

125. Lopes, M.S.; Araus, J.L. Comparative genomic and physiological analysis of nutrient response to $\mathrm{NH}_{4}{ }^{+}, \mathrm{NH}_{4}{ }^{+}: \mathrm{NO}_{3}{ }^{-}$and $\mathrm{NO}_{3}{ }^{-}$ in barley seedlings. Physiol. Plant. 2008, 134, 134-150. [CrossRef] [PubMed]

126. Redondo-Nieto, M.; Maunoury, N.; Mergaert, P.; Kondorosi, E.; Bolaos, L. Boron and calcium induce major changes in gene expression during legume nodule organogenesis. Does boron have a role in signalling? New Phytol. 2012, 195, 14-19. [CrossRef] [PubMed] 